\title{
OBEDUC: análise de aprendizagens docentes num contexto formativo sobre resolução de problemas
}

\author{
Douglas da Silva Tinti \\ Wanusa Rodrigues Ramos ${ }^{2}$ \\ Ana Lúcia Manrique 3 \\ Laurizete Ferragut Passos 4
}

Resumo: O presente artigo é resultado de um projeto de pesquisa do Programa Observatório da Educação (OBEDUC), aprovado no edital de 2012. Por entender-se a Aprendizagem da Docência como parte integrante do Desenvolvimento Profissional Docente, este artigo tem por objetivo apresentar uma análise de aprendizagens docentes de professores que ensinam matemática na educação básica, participantes de um processo formativo pautado na investigação, na elaboração, na avaliação, na experimentação e na implementação de atividades envolvendo a resolução de problemas. Foram analisados encontros realizados em 2013 que tiveram esta temática como fio condutor. Os instrumentos de coleta de dados foram gravações em áudio dos encontros do grupo. Entre as aprendizagens docentes apontadas, destacam-se fases do raciocínio pedagógico, planejamento do trabalho docente e implementação da estratégia de resolução de problemas.

Palavras-chave: resolução de problemas, aprendizagem da docência, formação de professores, Observatório da Educação

\section{OBEDUC: analysis of teacher learning in a formative context about problem solving}

\begin{abstract}
This article is the result of a research project approved at the Observatory of Education Program (OBEDUC), public notice 2012. As we understand the Teacher Learning as part of the Professional Development Teacher, this article aims to present an analysis of teacher learning who teach mathematics in basic education, participants of a formative process based on research; development; evaluation; testing and implementation of activities involving problem solving. The meetings held in 2013 that had this subject as a guide were analyzed. The data collection instruments were audio recordings of the group's meetings. Among the learning teachers identified, we highlight stages of pedagogical reasoning, teaching planning and implementation of problem solving strategy.
\end{abstract}

Keywords: problem solving, teacher learning, teacher education, Observatory of Education

1 Doutorando em Educação Matemática pela PUC-SP. Professor e Coordenador do Curso de Licenciatura em Matemática da Universidade Cidade de São Paulo. E-mail: douglastinti@uol.com.br

2 Doutoranda em Educação Matemática pela PUC-SP. Professora da Secretaria Municipal de Educação de São Paulo. E-mail: wanusa_rodrigues@hotmail.com

3 Doutora em Educação: Psicologia da Educação pela PUC-SP em 2003. Professora do Programa de Estudos Pós-Graduados em Educação Matemática da PUC-SP. E-mail: analuciamanrique@gmail.com

4 Doutora em Educação pela Universidade de São Paulo em 1997. Professora do Programa de Estudos Pós-Graduados em Formação de Formadores da PUC-SP. E-mail: laurizetefer@pucsp.br 


\section{Introdução}

O Programa Observatório da Educação (OBEDUC), criado pelo Decreto Presidencial $n^{\circ} 5.803$, de 08 de junho de 2006, é resultado da parceria entre a Coordenação de Aperfeiçoamento de Pessoal de Nível Superior (CAPES), o Instituto Nacional de Estudos e Pesquisas Educacionais Anísio Teixeira (INEP) e a Secretaria de Educação Continuada, Alfabetização, Diversidade e Inclusão (SECADI), com o propósito de fomentar a produção acadêmica e a formação de profissionais com pós-graduação stricto sensu em educação no Brasil.

Em conformidade com esse decreto, um dos objetivos do programa é fortalecer o diálogo entre a comunidade acadêmica, os gestores das políticas nacionais de educação e os diversos atores envolvidos no processo educacional. Temos entendido, também, que o OBEDUC tem se constituído, no cenário nacional, como uma política pública de formação para professores e futuros professores, uma vez que estreita o diálogo entre a comunidade científica e a comunidade escolar e, desse modo, desenvolve ações formativas considerando as demandas que emergem do contexto escolar.

No Edital 049/2012/CAPES/INEP, foi aprovado o Projeto em rede intitulado "Rede Colaborativa de práticas na formação de professores que ensinam matemática: múltiplos olhares, diálogos e contextos", que propõe a criação de uma rede colaborativa entre três Programas de Pós-Graduação (PPG), denominados núcleos, que possuem características distintas e fazem parte, respectivamente, da Educação (Universidade Federal de São Carlos - UFSCAR), da Educação Matemática (Pontifícia Universidade Católica de São Paulo - PUC-SP) e da Interdisciplinaridade (Universidade Federal do ABC - UFABC).

O núcleo constituído pela PUC-SP é formado pelo docente coordenador, por professores da universidade, estudantes de doutorado e de mestrado acadêmico, estudantes de graduação em Pedagogia e Licenciatura em Matemática e por professores em efetivo exercício nos anos iniciais e finais da rede pública de Educação Básica do Estado de São Paulo.

Trata-se, portanto, de um grupo heterogêneo, que visa privilegiar os múltiplos olhares, de profissionais de formações distintas e em diferentes momentos da carreira. Entendemos que a heterogeneidade é um aspecto que torna as reuniões do grupo um espaço muito rico, dada a possibilidade de todos aprenderem com as ideias, os conhecimentos e as habilidades de todos os membros.

No núcleo local da PUC-SP são realizadas reuniões quinzenais, nas quais é possível compartilhar saberes e práticas. Além disso, nesse espaço, os participantes entram em contato com teorias que subsidiam o trabalho e, ainda, compartilham de 
momentos de discussão que contribuem para ampliar a reflexão acerca da prática docente. É importante destacar que, ao mesmo tempo, procura-se desenvolver um ambiente amistoso, onde cada integrante se sente à vontade para expressar o que pensa e ouvir a opinião do outro.

As dinâmicas estabelecidas por esse grupo, em conjunto, caminham no sentido do descrito por Fiorentini (2013): “Na colaboração, todos trabalham conjuntamente ('co-laboram') e se apoiam mutuamente, visando atingir objetivos comuns negociados pelo coletivo do grupo. Na colaboração, as relações, portanto, tendem a ser não hierárquicas, havendo liderança compartilhada e 'co-responsabilidade' pela condução das ações” [destaque no original] (p. 56).

Esta concepção vai ao encontro do que as tendências atuais em pesquisas no campo da Educação Matemática têm apontado, ou seja, de que é indispensável, nos processos de formação de professores, dar ouvidos aos professores que estão atuando nas escolas públicas e que enfrentam diariamente os desafios e a complexidade da profissão docente. Haja vista que esses professores, em efetivo exercício docente, muito podem contribuir com sua experiência e seus saberes para o desenvolvimento de estudos sobre a prática.

Além disso, entendemos que, quando professores se inserem no meio acadêmico, participando de grupos de pesquisas em PPG, apresentando e compartilhando de diferentes olhares e experiências sobre o processo do ensino e aprendizagem da Matemática, muito têm a contribuir com a formação de professores, uma vez que, em contextos como esses, é possível desenvolver estudos teórico-metodológicos, elaborar recursos didáticos, refletir sobre estratégias de ensino, produzir narrativas, problematizar o processo formativo e refletir sobre a prática no sentido de aprimorá-la e melhorá-la.

Portanto, uma das metas do núcleo PUC-SP é a busca de significados que podem ser atribuídos ao trabalho colaborativo desenvolvido por acadêmicos, professores e alunos de graduação no âmbito do OBEDUC, como uma alternativa para a formação e para o desenvolvimento profissional de professores que ensinam matemática, pela articulação de diferentes saberes e pela socialização de múltiplos olhares sobre o fenômeno de aprender matemática e, mais do que isso, aprender a ensinar matemática.

\section{Aprendizagem da Docência - processo integrante do Desenvolvimento Profissional}

É sabido que a tarefa de formar professores tem se tornado cada vez mais complexa. Acreditamos que tal complexidade pode estar atrelada a diferentes fatores, como o desprestígio e a desvalorização da profissão docente - que acarreta 
a diminuição da procura pela carreira; a diversidade presente no contexto escolar, proveniente da ampliação da possibilidade de acesso das classes que antes não possuíam e para as quais a escola não havia sido concebida; o reconhecimento da multiplicidade de saberes necessários para sua atuação profissional; a disseminação e a utilização das novas tecnologias e a necessária tomada de decisão imediata e acertada diante de situações inusitadas no contexto escolar.

Além disso, não podemos desconsiderar que ensinar a ser professor tem sido, também, um grande desafio para os cursos de formação em nosso país, uma vez que as reformas curriculares, bem como os dilemas emergentes da sociedade atual, redefinem constantemente o papel do professor e, consequentemente, os seus saberes e as suas práticas.

A referência teórica sobre se tornar professor ainda não está coerente e abrangente, conforme foi verificado por Calderhead, citado por Mizukami et al. (2002):

não se dispõe, até o momento, de um referencial teórico coerente e abrangente, de uma teoria geral de conhecimento sobre a aprendizagem profissional que possa iluminar processos de desenvolvimento profissional de professores de modo a informar o desenho de cursos de formação básica e programas de formação continuada. (p. 48)

Nesse sentido, parece-nos pertinente não limitar à aquisição de conhecimentos e habilidades a preparação para tornar-se professor, ou seja, não basta apenas cursar uma licenciatura, em que são apresentados os conhecimentos e as habilidades necessárias para o exercício da docência. Tornar-se professor é mais amplo: envolve outros fatores, como, por exemplo, a identidade profissional. A esse respeito, apoiamos nossa reflexão na concepção de Tancredi (2009) de que:

Aprender a ensinar envolve adquirir conhecimentos profissionais relacionados ao nível de ensino e às disciplinas/componentes curriculares pelos quais um professor se responsabiliza. Tornar-se professor é mais do que isso, pois envolve assumir as responsabilidades que emergem da prática profissional numa determinada instituição educativa, ou seja, comprometer-se com uma escola e seu contexto. Ser professor não cessa quando as aulas terminam; exige participação na escola e colaboração com os pares, exige assumir uma atitude pró-ativa frente aos estudantes, às diferentes classes que atua, aos projetos pedagógicos das escolas. (p.15)

Desse modo, concordamos com Lima et al. (2003) que, embora se reconheça a importância de investigar e compreender como se dá a aprendizagem profissional da docência, esse objeto de investigação tem merecido menos atenção por parte da pesquisa na área de Formação de Professores, no cenário nacional. 
Diante desses resultados e das constatações apresentadas por Lima et al. (2003), percebemos que esta é uma temática pouco explorada no âmbito da formação de professores e da própria Educação Matemática no Brasil.

Por compreendermos a importância de investigar esse processo, uma pergunta possível consistiria em “como se aprende a ser professor?". Como dito anteriormente, precisamos ter clareza de que não se aprende a ser professor do dia para a noite ou, simplesmente, cursando uma licenciatura. Nas palavras de Zeichner (1993),

aprender a ensinar é um processo que continua ao longo da carreira docente e que, não obstante a qualidade do que fizemos nos nossos programas de Formação de Professores, na melhor das hipóteses só poderemos preparar os professores para começar a ensinar. (p.55)

Nessa direção, Mizukami et al. (2002) relatam que a produção sistêmica de pesquisas voltadas para a Aprendizagem da Docência e para o conhecimento profissional do professor tem indicado que

aprender a ensinar é desenvolvimental e requer tempo e recursos para que os professores modifiquem suas práticas; que as mudanças que os professores precisam realizar de forma a contemplar novas exigências sociais e de políticas públicas vão além de aprender novas técnicas, implicando revisões conceituais dos processos educacionais e instrucional e da própria prática [destaque no original]. (p.48)

Entre as possíveis aprendizagens docentes, encontramos em Shulman (1987, 1986) a noção de raciocínio pedagógico que foi apresentada, de maneira sintética por Mizukami et al. (2002):

- Compreensão: o raciocínio pedagógico tem início com a compreensão, ou seja, com o entendimento crítico de conceitos da mesma disciplina ou de disciplinas de domínios relacionados; compreensão de propósitos, matéria, de sua estrutura, de idéias relacionadas - direta ou indiretamente - à disciplina em pauta.

- Transformação: envolve interpretação (revisão dos materiais instrucionais à luz das próprias compreensões do conteúdo específico da área); representação (repertório que inclui exemplos, analogias, atividades diferenciadas, ilustrações, metáforas, demonstrações, explicações etc., a serem usados de acordo com a situação na transformação do conteúdo para a ilustração); adaptação (ajuste dessa transformação às características dos alunos em geral - estilos de aprendizagem, etnia, gênero, motivação, idade, conhecimentos prévios etc.); e consideração de casos específicos (adaptação do material e de procedimentos 
aos estudantes específicos da classe). Esses processos produzem planos ou conjunto de estratégias para o ensino.

- Instrução: consiste no manejo de classe, em exposições e em interações e considera outros aspectos do ensino ativo, como: trabalhos em grupo, disciplina, humor, questionamentos, descoberta, investigação e formas observáveis de ensino na classe.

- Avaliação: consiste na checagem da compreensão dos alunos durante o ensino interativo, no teste da compreensão dos alunos no final das unidades e na avaliação de seus desempenhos, assim como ajuste às experiências curriculares. Ocorre durante e após a instrução.

- Reflexão: consiste no processo de aprendizagem a partir da própria experiência, quando os professores avaliam seu trabalho.

- Nova compreensão: consiste em compreensão aperfeiçoada, enriquecida, formando um círculo completo, a partir do ponto de partida [destaque nosso]. (pp.70-71)

Diante do cenário educacional atual, parece-nos que há uma renovação de saberes, práticas e valores que influenciam diretamente os processos de formação de professores. A partir dessa ideia podemos inferir que a Aprendizagem da Docência é um processo integrante do desenvolvimento profissional e da própria profissionalidade docente (Tinti, 2012).

\section{Caminhos percorridos}

No primeiro semestre de 2013, após a aprovação do projeto "Rede colaborativa de práticas na formação de professores que ensinam matemática: múltiplos olhares, diálogos e contextos", no âmbito do Programa Observatório da Educação (OBEDUC), constituímos um grupo de trabalho composto por: três professores dos anos iniciais da Educação Básica, três professores de Matemática dos anos finais da Educação Básica; três alunos do curso de Pedagogia; três alunos do curso de Licenciatura em Matemática; dois doutorandos e um mestrando em Educação Matemática; um mestrando em Educação; e uma doutora (coordenadora do projeto). Este grupo se reúne quinzenalmente aos sábados na PUC-SP. Em todos os encontros é feita a gravação em áudio, para subsidiar pesquisas futuras.

A temática Resolução de Problemas foi eleita pelo grupo como objeto de estudos, reflexões e desenvolvimento de atividades práticas a serem desenvolvidas ao longo dos dez encontros previstos para o segundo semestre de 2013.

Sendo assim, no primeiro encontro foi proposta ao grupo a realização de um mapeamento bibliográfico sobre esta temática para, posteriormente, realizarmos uma sociali- 
zação, com o objetivo de fazer uma síntese das pesquisas produzidas e de compartilhar compreensões e questionamentos que emergiram do estudo sobre a Resolução de Problemas. Algumas das referências consultadas pelos professores e licenciandos do grupo foram Dante (2002), Onuchic (1999), Polya (1978) e os Parâmetros curriculares nacionais (MEC, 1997, 1998).

Nesse momento de socialização, no segundo encontro, o grupo sinalizou a necessidade de vivenciar uma experiência prática com uma atividade elaborada a partir dos princípios da Resolução de Problemas (MEC, 1997, p. 33) e elegeu o conceito matemático frações como ponto de partida.

No terceiro encontro, dividimos os integrantes do grupo em dois subgrupos mistos (com alunos de graduação e professores da educação básica) e solicitamos que realizassem essa elaboração. A atividade poderia ser pensada para qualquer ano/série da educação básica. Um dos grupos pensou em uma atividade para alunos do 6o ano do ensino fundamental, utilizando um material manipulável denominado “disco de frações”, e o outro elaborou para os alunos do $5^{\circ}$ ano do ensino fundamental uma atividade que solicitava que medissem uma determinada mesa apenas com um pedaço de papel fornecido pelo professor, por exemplo, uma folha de papel sulfite.

No quarto encontro, pedimos que cada grupo simulasse a aplicação dessa atividade com os membros do outro grupo, encarregado da outra elaboração.

Já no quinto encontro foi realizada uma reflexão sobre o que foi possível aprender com essa dinâmica.

Após esse movimento, os professores retomaram as atividades, com o objetivo de planejar novamente e, posteriormente, propor as novas atividades para alunos da Educação Básica. Esse movimento não será por nós analisado neste artigo, pois será objeto de investigação de outros trabalhos.

Sendo assim, o presente texto tem por objetivo analisar as aprendizagens da docência reveladas pelos professores e futuros professores, que ensinam ou ensinarão matemática na educação básica, após a vivência de um processo formativo pautado na investigação, na elaboração e na experimentação de atividades envolvendo a Resolução de Problemas.

Para atingir esse objetivo, foram transcritos e analisados os diálogos do quinto encontro do segundo semestre de 2013. Com o objetivo de manter o anonimato dos integrantes, denominaremos de: a) PAI os professores dos anos iniciais do ensino fundamental, b) PAF os professores dos anos finais do ensino fundamental, c) AM os alunos do curso de licenciatura em matemática e d) AP os alunos do curso de Pedagogia.

\section{Apresentação e análise dos dados}

Ao considerar a experiência vivenciada pelo grupo, um primeiro aspecto da Aprendizagem da Docência revelado pelos participantes refere-se ao movimento 
de planejamento do trabalho docente, que está diretamente relacionado com o raciocínio pedagógico, sobretudo no que tange à instrução, já que envolveu interações e, além disso, considerou aspectos como o trabalho em grupo, a descoberta e a investigação (Shulman, como citado em Mizukami et al., 2002, p.71).

Ao refletirem sobre os encontros e as atividades propostas por um dos grupos, que envolviam a utilização do material manipulável disco de frações, um dos integrantes do grupo apontou um erro que pode acontecer com qualquer professor, se a atividade não for bem planejada: "eles deram os disquinhos ... o primeiro exercício deu para fazer com os disquinhos, e o segundo não deu” (PAF 1, 5 encontro, 2o sem. 2013).

Como a proposta de um dos grupos era utilizar os "discos de frações" para solucionar algumas situações-problema, o grupo não atentou para o fato de que esse material manipulável possui uma limitação, no que diz respeito à representação de números fracionários, ou seja, representa frações com denominadores até 10. Por esse fato, outro integrante ressaltou:

É preciso testar o material antes porque, por exemplo, o nosso grupo não trouxe material e usou os discos de frações que estavam aqui, só que mesmo usando esse, eu não me atentei que não tinha um disco de 12, aí não dava para chegar à resposta correta. (PAF 3, 5o encontro. 2o sem. 2013)

Nas discussões realizadas, os integrantes ressaltaram a importância de o professor conhecer bem o material e a atividade que utilizará em sua prática, para que o objetivo traçado seja alcançado, uma vez que essa utilização implica em processos como interpretação e adaptação, apontados por Shulman, citado em Mizukami et al. (2002, p. 71). Identificamos que nas duas atividades propostas houve esta necessidade:

por exemplo, também, se você pede para medir a mesa com uma folha de sulfite, você tem que saber qual é a medida da mesa, porque senão pode cair num número que não seja fracionário, pode dar 3 folhas, aí não tem desafio nenhum, aí acabou sua aula e não chegou naquele ponto que você queria. (PAF 3, 5o encontro, 2o sem. 2013)

Além desses aspectos levantados, um dos AP, que na ocasião cursava o segundo semestre do curso, compartilhou com o grupo o seguinte questionamento: "eu fiquei com uma dúvida na minha mente e formulei a seguinte pergunta, se existe, pra quem já tá na prática, uma grade curricular: O professor tem que dar conta de tudo até o final do ano? Como funciona?” (AP 3, 5o encontro, 2o sem. 2013). 
Diante dessa indagação, discutiu-se a importância de o professor conhecer o currículo prescrito (Sacristán, 200o) e, também, o alunado. Atrelada ao planejamento, os integrantes ressaltaram a importância de o professor ter clareza da intencionalidade da proposta de atividade.

eles passaram uma atividade de soma de frações para o nosso grupo e deram os disquinhos e disseram: - "Vai, faz!". Aí eu lembro que eu até falei para o pessoal: se eu já sei somar fração sem usar os discos, eu vou brincar com eles”. (PAF 1, 5o encontro. 2o sem. 2013)

Ao utilizar um material manipulável nas aulas de matemática, como aponta Lorenzato (2006), o professor tem a intencionalidade de promover a aprendizagem utilizando atividades que contemplam e favorecem processos como classificar, analisar, conjecturar, experimentar, testar, construir, dentre outros.

quando você para para pensar em uma atividade destas, de Resolução de Problemas, quantos desdobramentos ela pode ter, ela passa a ser uma sequência didática [...] olhar para atividade, pensar sobre ela, refletir nela, quantas coisas a gente pode fazer [...] enquanto professora na sala de aula, às vezes você não tem este tempo. (PAI 1, 5o encontro, 2oㅡㅁ sem. 2013)

Um dos objetivos traçados, reiteramos, foi o de vivenciar uma atividade embasada na Resolução de Problemas. Nesse sentido, o PAI 1 ressaltou os desdobramentos que uma atividade pensada nessa perspectiva proporciona. Além disso, destaca a importância de momentos de reflexão, planejamento e experimentação coletiva e compartilhada, entendendo esse movimento como potencializador da formação docente. Este aspecto se assemelha à fase de reflexão apontada por Shulman, citado em Mizukami et al., (2002, p.71), como parte integrante do raciocínio pedagógico.

Ao longo desse percurso formativo, foi possível constatar que há diferentes formas de conceber a Resolução de Problemas (Smole \& Diniz, 2001), de acordo com a finalidade da atividade.

A resolução de problemas ela tem essas várias faces, eu lembro até de um texto que falava das várias faces, só que o pessoal ficou tanto na cabeça com essa questão de usar a resolução de problemas para ensinar, que esqueceu o outro lado, aí ficou nisso, o questionamento se a atividade do outro grupo era ou não é resolução de problemas, claro que é!. (PAF 3, 5o encontro, 2o sem. 2013)

Diante da fala do PAF 3, vale a pena ressaltar o percurso estabelecido pelo grupo (investigação - elaboração - experimentação). Esse percurso contribuiu para 
o amadurecimento teórico dos integrantes do grupo: despertou neles um olhar analítico para as atividades, de modo a identificar se uma determinada atividade pode ou não ser desenvolvida segundo os princípios da Resolução de Problemas. Assim, concordamos com Manrique e Perentelli (2008), quando afirmam que discutir a relação teoria-prática significa se propor a "pensar no processo de construção de sua autonomia intelectual: o professor além de saber e de saber fazer deve compreender o que fazer" (p. 11676).

Dentre esses princípios, um dos integrantes ressaltou o papel e a condução do professor diante de uma atividade elaborada na perspectiva da Resolução de Problemas: " a condução de uma atividade como essa de resolução de problemas às vezes pode ser uma coisa muito aberta. Como eu, que sou um professor que gosto de ter o controle da situação, lido com esse desequilíbrio?" (PAI 3, 5o encontro, 2oㅡㄴ sem. 2013).

No contexto da Resolução de Problemas, o professor é visto como um mediador da aprendizagem: ele não dá a resposta pronta aos alunos, mas os provoca com questionamentos que contribuam para o desencadeamento de um pensamento lógico, a fim de conduzir o aluno à solução do problema proposto. E essa atitude nem sempre é tranquila para o professor.

A PAF2 explicava bastante. Eu dizia pra ela ficar quieta, que ela não tinha que explicar o problema. (PAF 3, 5 encontro, 2o sem. 2013)

Eu queria falar para eles que era para fazer o cálculo, a PAF 2 não deixava eu abrir a boca, foi difícil me controlar. (PAF 2, 5o encontro, 2ำ sem. 2013)

Como podemos perceber nos diálogos transcritos anteriormente, todos de integrantes de um mesmo grupo, essa postura de mediador pode ser um dos obstáculos que o professor pode enfrentar ao optar por desenvolver uma atividade seguindo a perspectiva da Resolução de Problemas; e pode se constituir em um desafio. No entanto, pode representar o ponto de partida para a fase indicada por Shulman como nova compreensão desta feita mais aperfeiçoada e enriquecida - sobre as estratégias de ensino da matemática (Mizukami et al., 2002, p.71).

Diante do que foi exposto até aqui, ressaltamos a importância de espaços formativos como esse, uma vez que "os professores demonstram muita resistência em falar de suas práticas aos colegas. É preciso que haja relações de confiança que pressuponham ligações de amizade ou a sensação de fazer parte integrante de uma equipe pedagógica” (Perrenoud, 1994, p.33).

Desse modo, dependendo da forma como são organizados os projetos no âmbito do OBEDUC, podemos concebê-lo como um (novo) locus de Aprendizagem da Docência e, consequentemente, de Desenvolvimento Profissional. 


\section{Considerações Finais}

Partimos do ponto de vista de que o Desenvolvimento Profissional Docente e, consequentemente, a Aprendizagem da Docência são processos contínuos e plurais. Nesse contexto, a prática passa a ser concebida como ponto de partida e de chegada da formação profissional, tendo a teoria, a pesquisa e a colaboração como mediação (Fiorentini \& Nacarato, 2005).

Analisando a trajetória do grupo OBEDUC PUC-SP, é possível pontuar mais uma aprendizagem, que é a experiência pautada numa vivência na prática. Ademais, esta aprendizagem foi significativa e indispensável para dar continuidade ao processo formativo proposto.

Evidenciou-se que a dinâmica assumida pelo núcleo da PUC-SP - de investigação, elaboração, avaliação, experimentação e implementação de atividades envolvendo a resolução de problemas - está diretamente relacionada com o desenvolvimento do raciocínio pedagógico, proposto por Shulman (1986, 1987), além de possibilitar uma vivência prática com a metodologia de Resolução de Problemas.

É importante sinalizar, também, que essa vivência desencadeou nos envolvidos um processo de (re)significação de conceitos matemáticos, dentre eles o de número fracionário, dado que as atividades desenvolvidas tinham esse conceito como ponto de partida.

Concordamos com Ramos (2015), quando defende que pesquisas sobre grupos de professores, como este do OBEDUC PUC-SP, podem ser um indicativo para as políticas públicas de formação de professores quanto à potencialidade desses espaços, na contramão de ações de formação pautadas no modelo de cursos de treinamento e palestras, marcadas, muitas vezes, pela ausência de situações que oportunizem o compartilhamento de experiências entre os professores.

Por esse motivo, destacamos que, no âmbito nacional, há muitos projetos financiados pelo OBEDUC e, portanto, temos, por meio deles, a possibilidade de oportunizar não só pesquisas acadêmicas, mas também espaços formativos plurais que promovam aprendizagens da docência e compartilhamento de saberes, contribuindo com o Desenvolvimento Profissional de todos os envolvidos e com a Formação de Professores em nosso país.

\section{Referências}

Dante, L. R. (2002). Didática da resolução de problemas de Matemática. São Paulo: Ática.

Fiorentini, D. (2013). Pesquisar práticas colaborativas ou pesquisar colaborativamente? In M. C. Borba, \& J. L. Araújo (Orgs.), Pesquisa qualitativa em Educação Matemática (pp.53-85). Belo Horizonte, MG: Autêntica. 
Fiorentini, D., \& Nacarato, A. M. (2005). Introdução: Investigando e teorizando a partir da prática a cultura e o desenvolvimento de professores que ensinam matemática. In D. Fiorentini, \& A. M. Nacarato (Org.), Cultura, formação e desenvolvimento profissional de professores que ensinam matemática (pp.7-17). São Paulo, SP: Musa.

Lima, E. F., Terrazzan, E. A., Garrido, E., Brzezinski, I., Núñez, I. B., Passos, L. F., \& Ribas, M. H. (2003). Análise dos trabalhos apresentados no GT08 no período de 1999 a 2003 (Trabalho encomendado). In 26 Anais da Reunião Anual da ANPEd. Poços de Caldas, MG, Brasil.

Lorenzato, S. A. (2006). Laboratório de ensino de Matemática e materiais didáticos manipuláveis. In S. A. Lorenzato (Org.), O laboratório de ensino de Matemática na formação de professores (pp.3-38). Campinas, SP: Autores Associados.

Manrique, A. L., \& Perentelli, L. F. (2008). Um estudo sobre a prática como componente curricular em cursos de licenciatura em matemática. In 8 Anais do Congresso Nacional de Educação. Curitiba, PR, Brasil. Retirado em 26 de janeiro de 2016, de http://www.pucpr. br/eventos/educere/educere2008/anais/pdf/737_526.pdf

Ministério da Educação. Secretaria de Educação Fundamental. (1997). Parâmetros Curriculares Nacionais: Matemática (Vol. 3, 1o e 2o ciclos do ensino fundamental). Brasília: Autor.

Ministério da Educação. Secretaria de Educação Fundamental. (1998). Parâmetros Curriculares Nacionais: Matemática (3o e 4o ciclos do ensino fundamental). Brasília: Autor.

Mizukami, M. G. N., Reali, A. M. M. R., Reyes, C. R., Martucci, E. M., Lima, E. F., Tancredi, R. M. S. P., \& Mello, R. R. (2002). Escola e aprendizagem da docência processos de investigação e formação. São Carlos, SP: EdUFSCar.

Onuchic, L. R. (1999). Ensino-aprendizagem de Matemática através da resolução de problemas. In M. A. V. Bicudo (Org.), Pesquisa em Educação Matemática: concepções e perspectivas (pp.199-218). São Paulo, SP: Unesp Editora.

Perrenoud, P. (1994). La formation des enseignants entre théorie et pratique (Savoir et Formation). Paris: L'Harmattan.

Polya, G. (1978). A arte de resolver problemas (H. L. Araújo, Trad.). Rio de Janeiro: Interciência.

Ramos, W. R. (2015). Observatório da Educação da PUC/SP e a formação de professores que ensinam matemática em Comunidades de Prática. Dissertação de Mestrado em Educação Matemática, Pontifícia Universidade Católica de São Paulo, São Paulo, SP, Brasil. Retirado em 26 de janeiro de 2016, de http://www.sapientia.pucsp.br/tde_busca/arquivo. php?codArquivo $=18490$

Sacristán, J. G. (2000). O currículo: uma reflexão sobre a prática (3a ed.). Porto Alegre: Artmed.

Shulman, L. S. (1986). Those who understand: knowledge growth in teaching. Educational Researcher, 15(2), 4-14.

Shulman, L. S. (1987). Knowledge ant teaching: foundations of a new reform. Harvard Educational Review, 57(1), 1-21.

Smole, K. S., \& Diniz, M. I. (2001). Ler, escrever e resolver problemas: habilidades básicas para aprender matemática. Porto Alegre: Artmed.

Tancredi, R. P. (2009). Aprendizagem da docência e profissionalização: elementos de uma reflexão. São Carlos: EdUFSCar. 
Tinti, D. S. (2012). PIBID: um estudo sobre suas contribuições para o processo formativo de alunos de Licenciatura em Matemática da PUC-SP. Dissertação de Mestrado em Educação Matemática, Pontifícia Universidade Católica de São Paulo, São Paulo, SP, Brasil. Retirado em 26 de janeiro de 2016, de: http://www.sapientia.pucsp.br/tde_busca/arquivo. php?codArquivo=14876

Zeichner, K. M. (1993). A formação reflexiva de professores: ideias e práticas. Lisboa: Educa.

Submetido em: 29/01/2016

Aceito em: 24/02/2016 
